\title{
Effect of Rainfall Trend on Yam Yield in Mokwa Local Government Area of Niger State, Nigeria
}

\author{
Mohammed J Mamman* \\ Department of Agricultural Technology, College of agriculture Mokwa, Nigeria
}

*Corresponding author: Mohammed J Mamman, Department of Agricultural Technology, College of Agriculture Mokwa, Nigeria

Submission: 監 December 04, 2017; Published: 僵 February 26, 2018

\begin{abstract}
Agricultural production in Niger State like other states in Nigeria is highly vulnerable to climate changeability. Climate change is predicted to have adverse effects on the agricultural sector of the poorer parts of the world especially sub-Saharan Africa. The aim of the study is to investigate and analyse the effect of rainfall trend on the production of yam in Mokwa local government area of Niger state, Nigeria. For the purpose of this research, data were collected from 100 respondents through the administration of questionnaires. Rainfall data covering a period of thirteen years (2003-2015) were also obtained from College of Agriculture Mokwa weather station, while the yearly yam yield for 16 years (2000-2015) was obtained from Niger State Ministry of Agriculture. Linear regression models and standardized anomaly index were used to analysis the data gathered. The study showed that the trend of mean annual rainfall in the study area was minimal but significant with $\mathrm{R}^{2}$ value of 0.8 for mean monthly rainfall. A strong relationship between rainfall variation and yam yield exist with $r^{2}$ value of 0.881 . The variation in the yield among the years was moderately significant with $\mathrm{R}^{2}$ value of 0.5064. It also showed a positive response between yam yield and moderate rainfall that was well distributed. Extension agent from ministries of agriculture and ADPs should do more in harnessing relevant information on food production in all the local government areas of Niger state so as to build a robust data bank for further research.
\end{abstract}

Keywords: Climate change; Variability; Analysis; Scandalized anomaly index

\section{Introduction}

Yams (Dioscorea species) constitute the predominant starchy staple in sub-Saharan Africa where food security for a growing population is a critical issue. Yam cultivation has excessively expanded over time in Niger State. In 1978, the estimated yam production of the state was 230,107 tonnes [1], and it grew by $1.936 \%$ to $4,685,810$ tonnes in 2007 [2]. Annual agricultural production is subjected to large variations due to risk and uncertain factors completely beyond the farmer's control. This is the reason why the management of farm enterprise is much more complex than the management of industries. These factors complicate management decisions in agricultural production and affect farmer's decision in production and marketing [3].

Climate is described as change as long-term in the statistical distribution of weather pattern over a period of time that ranges from decade to millions of years [4]. Change in climate and consequent global warming are posing threats to food security in many developing nations including Nigeria because of the climate-dependent nature of agricultural systems and lack of coping capabilities. It is one of the most serious environmental threats facing mankind worldwide. It affects agriculture in several ways, including its direct impact on food production. Climate change, which is attributable to the natural climate cycle and human activities, has adversely affected agricultural productivity in Africa [5].
The rainfall characteristics in Nigeria have been examined for secular change that is, dominant trend notably by Olaniran et al. [6] and by Olaniran [7] and the results show that there has been a progressive early retreat of rainfall over the whole country spanning up to a half a century now and consistent with this pattern there has also been a significant decline of rainfall frequency that is, the number of rain days in September and October which respectively coincide with the end of the rainy season in the northern and southern parts of the country. Furthermore, the combined effect of these declines was found to lead to a significant decrease in annual rain days over the whole country. In effect, except farmers change to early maturing crop varieties, streamline their farming calendars with the changing rainfall regime or have access to irrigation water, the secular changes in rainfall frequency for the country pose serious threat to the maturity of annual crops and consequently to food security for the nation. Hence, the volatility of agricultural output due to rainfall fluctuation can mean a large burden for the low-income farming households [8].

The Northern zone faces the threat of desert encroachment at a very fast rate per year occasioned by fast reduction in the amount of surface water, flora and fauna resources on land [9]. This makes people to exploit more previously undisturbed lands leading to depletion of the forest cover and increase on sand dunes/Aeolian 
deposits in the Northern axis of Nigeria. On the other hand, those in coastal region are vulnerable to incessant floods, destruction of mangrove ecosystems, contamination of water and transmission of water borne diseases, leading to displacement and communal crisis [10]. The resource poor farmers therefore faced the prospects of tragic crop failures which reduced agricultural productivity, increased hunger, poverty, malnutrition and diseases [11]. International institute for tropical Agriculture (IITA) have developed various new technologies to produce yams in Africa during dry season [12]. The ecological constraints of the savanna zones have been overcome by the spontaneous effort of farmers to pick out the early maturing cultivars that adapt to short rainfall period [13]. This study investigates the effect of rainfall trend pattern in the study area analyse the effect of the rainfall trend on yam production in the area and advice on possible measures to take in ameliorating the trend effect [14].

\section{Methodology}

\section{Description of the study area location}

Mokwa is a Local Government Area in Niger State, Nigeria. The southern border of the LGA is formed by the Niger River from Lake Jebba in the west beyond the confluence of the Kaduna River in the East. Kwara State and Kogi State are across the Niger from the LGA. It has an area of $4,338 \mathrm{~km}^{2}$ and a population of 244,937 at the 2006 census. It is located at an elevation of 88 meters above sea level and its population amounts to 244,937. It has two major districts, Kede and Mokwa with a total of 98 and 45 villages respectively. Out of the 143 villages 108 (78\%) are yam producers. Its coordinates are $9^{\circ} 16^{\prime} 60^{\prime \prime} \mathrm{N}$ and $5^{\circ} 3^{\prime} 0^{\prime \prime} \mathrm{E}$ in DMS (Degrees Minutes Seconds) or 9.28333 and 5.05 (in decimal degrees) (Figure 1).

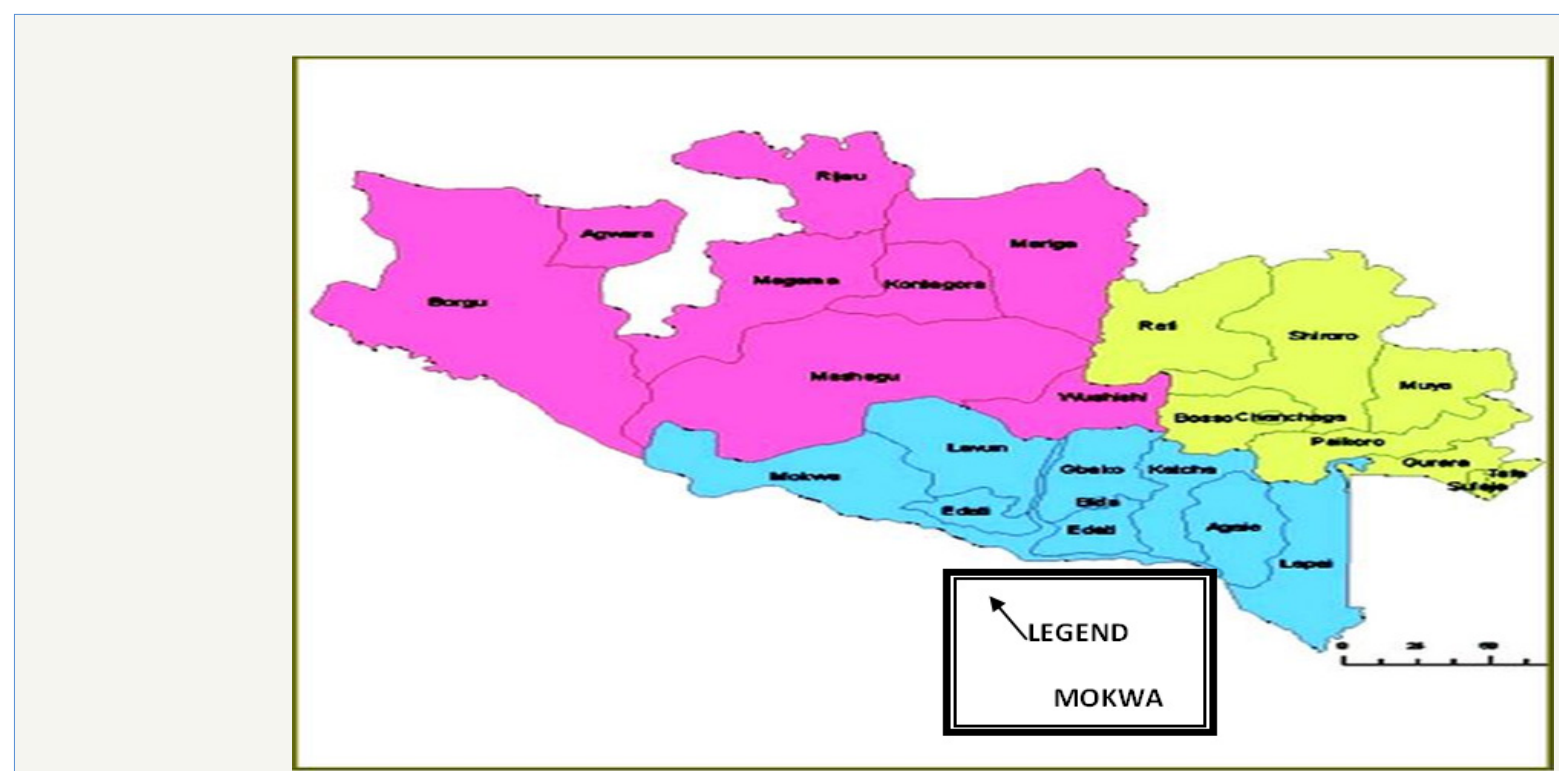

Figure 1: Map of the study area. Source: (Wikipedia 2012).

\section{Climate and agro-ecology}

Mokwa local Government experiences two distinct seasons, the dry and wet seasons. The annual rainfall varies from about $1000 \mathrm{~mm}$ in the south to $1,200 \mathrm{~mm}$. The duration of the rainy season ranges from 150 to 210 days. Mean maximum temperature remains high throughout the year, hovering about 32 ${ }^{\circ} \mathrm{F}$, particularly in March and June. However, the lowest minimum temperatures occur usually between December and January when most parts of the state come under the influence of the tropical continental air mass which blows from the north. Dry season commences in October.

\section{Sampling design and sample size}

The study employed multistage sampling technique. First stage involve purposive selection of ten (10) wards that are rural based, in each of this ward two (2) villages were randomly selected making a total of 20 villages selected for the study in the area, second stage involve random selection of five (5) yam farmers from each of the selected villages in the local government area which make a total of one hundred (100) respondents that constituted the sample size of the study.

\section{Statistical and data analysis}

Precipitation data were obtained for thirteen years (20032015) from Niger State College of Agriculture Mokwa weather station. Data collected were subjected to descriptive statistical analysis. Rainfall data obtained were on monthly basis converted to mean annual values using the statistical technique stated below.

$$
X \propto=X n
$$

Where $=$ Mean

$\mathrm{n}=$ number of years

$\sum=$ Summationsign

Standardized anomaly index and linear regression models were employed to examine the relationship between rainfall variability and yam production of the study area. The formula for 
the standard anomaly index is given as:

$$
S A I=x / \sigma
$$

Where

$\bar{X}=$ mean

$\mathrm{x}=$ rainfall on yearly basis

$$
\sigma=\text { standard deviation }
$$

The formula for the linear regression is given as:

$$
y=a+b x
$$

Where:

$$
\begin{aligned}
& a=y \alpha-b x a \\
& b=\left(N \sum x y-\sum x \sum y\right) /\left(N \sum x^{2}-\left(\sum x\right)^{2}\right.
\end{aligned}
$$

$\mathrm{y}=$ Planting tine of the year

$\mathrm{x}=$ Rainfall trend

\section{Results and Discussion}

\section{Rainfall distribution in Niger state college of agriculture Mokwa station}

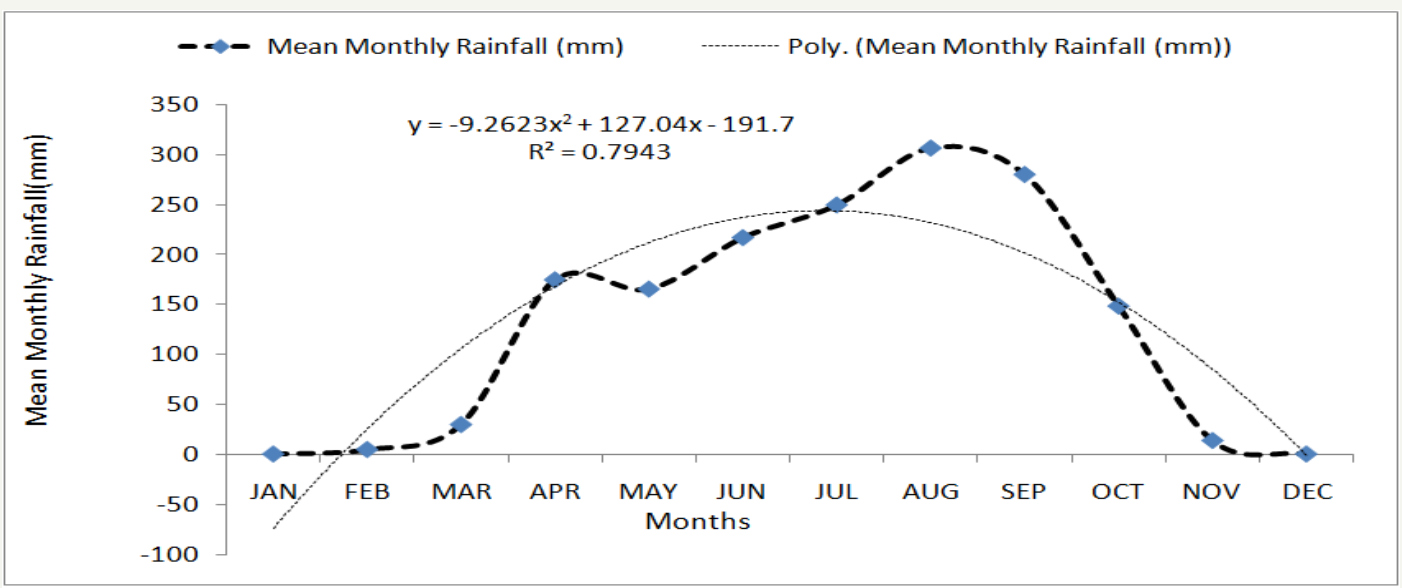

Figure 2: Mean monthly rainfall of Niger state college of Agriculture Mokwa Station.

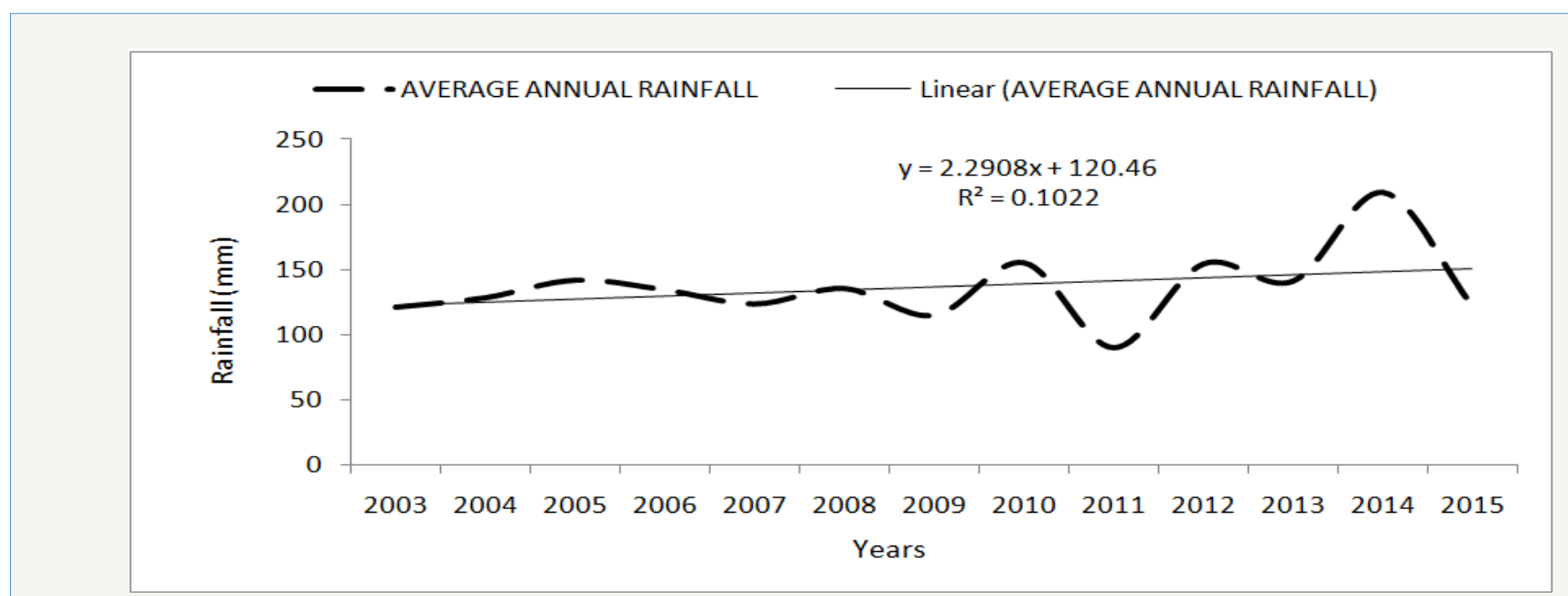

Figure 3: Pattern of Mean annual Rainfall of Niger State College of Agriculture Mokwa Station, (2003 - 2015)

Figure 2 shows average Monthly rainfall of Niger State college of Agriculture Mokwa, the months of January shows no rainfall while February has the least with a rainfall of $4.5 \mathrm{~mm}$ and August has the highest with $306.4 \mathrm{~mm}$. The $\mathrm{R}^{2}$ value of 0.8 indicate significant trend within the months of rainfall. Shows a thirteen years mean annual rainfall of Niger State College of Agriculture Mokwa, with 2003 having the least $(1335 \mathrm{~mm})$ total rainfall and average of $121.3636 \mathrm{~mm} .2014$ has the highest rainfall of $2514 \mathrm{~mm}$ and average of $121.7917 \mathrm{~mm}$. This is also depicted in Figure 3. It could be observed that well establishment rain starts in the month of April and incipient in November. The time of planting is very critical in development of Yam. Farmers from the study area based on personal interaction and questionnaires applied commenced planting in the month of March or April and harvest in the months of August or September. Incipientor lack of establishment of rainfall during the Months of March or April has 
resulted to farmers recording significant Yam loses. Adjustment in planting date to well established months of rainfall is necessary to avoid spoilage. Planting can commence in the months of April-
May to June and harvest in the months of November-December (Figure 4).

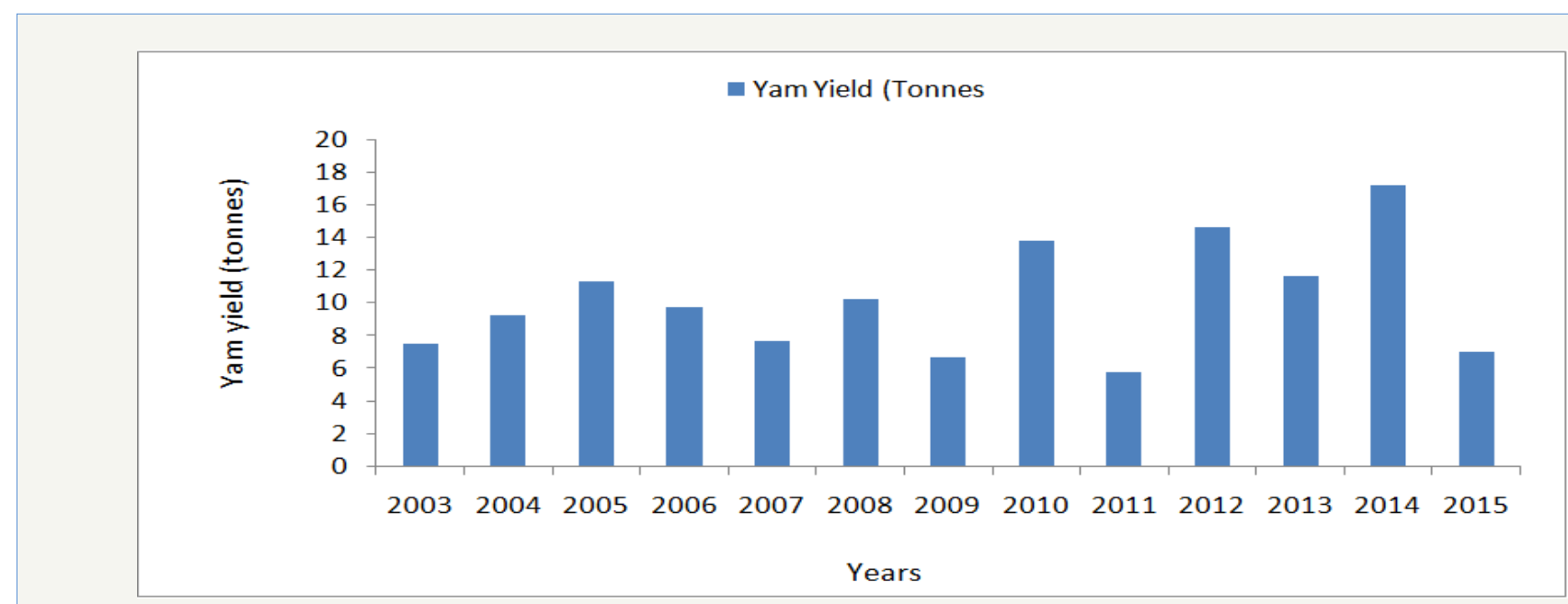

Figure 4: Yield of yam (tones) in the study area.

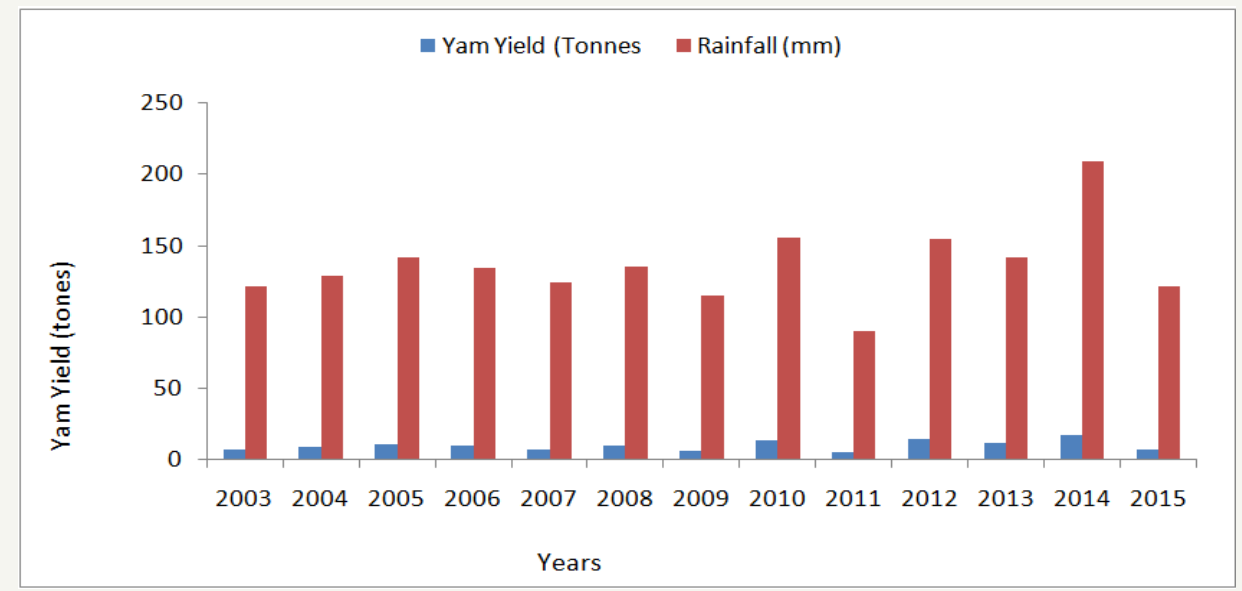

Figure 5: Relationship between yam yield and average annual rainfall of Mokwa.

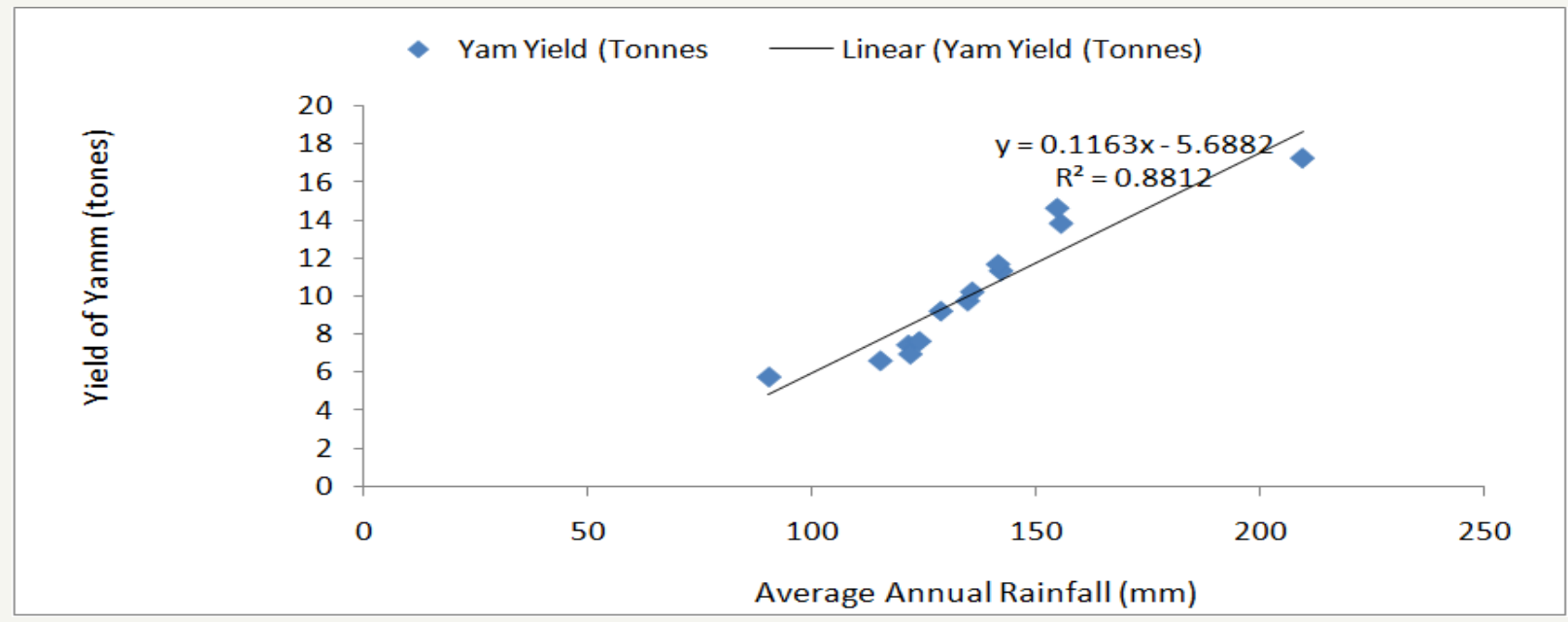

Figure 6: The relationship between the annual rainfall and yam yield. 
Figure 5 shows the relationship between yam yield and average annual rainfall of Mokwa, the relationships indicates that as the rainfall increases the yam yield also increases. 2014 has the highest yield (17.24 tonnes) as a result of the highest rainfall in the year (209.5). While 2009 has the lowest yield (6.63 tonnes) as a result of the lowest rainfall in the year $(115.1 \mathrm{~mm})$. Figure 6 shows the relationship between annual rainfall and yam yield, the figure indicate strong relationship between the variables with $\mathrm{r} 2$ value of 0.881 which is close to 1 . It also shows that rainfall has strong influence on yam yield in the area.Although inadequacies of farm inputs like improved seeds, fertilizer, herbicides and the required management are contributing factors to yam yield as indicated by the farmers during oral interview, the importance of adequate rainfall to yam yield cannot be overemphasized as shown from the study. (Figure 7) depicts variability and relationship between yam yield and years of production. The $\mathrm{r}^{2}$ value of 0.5064 shows that there is no strong variation within the years of yam production.

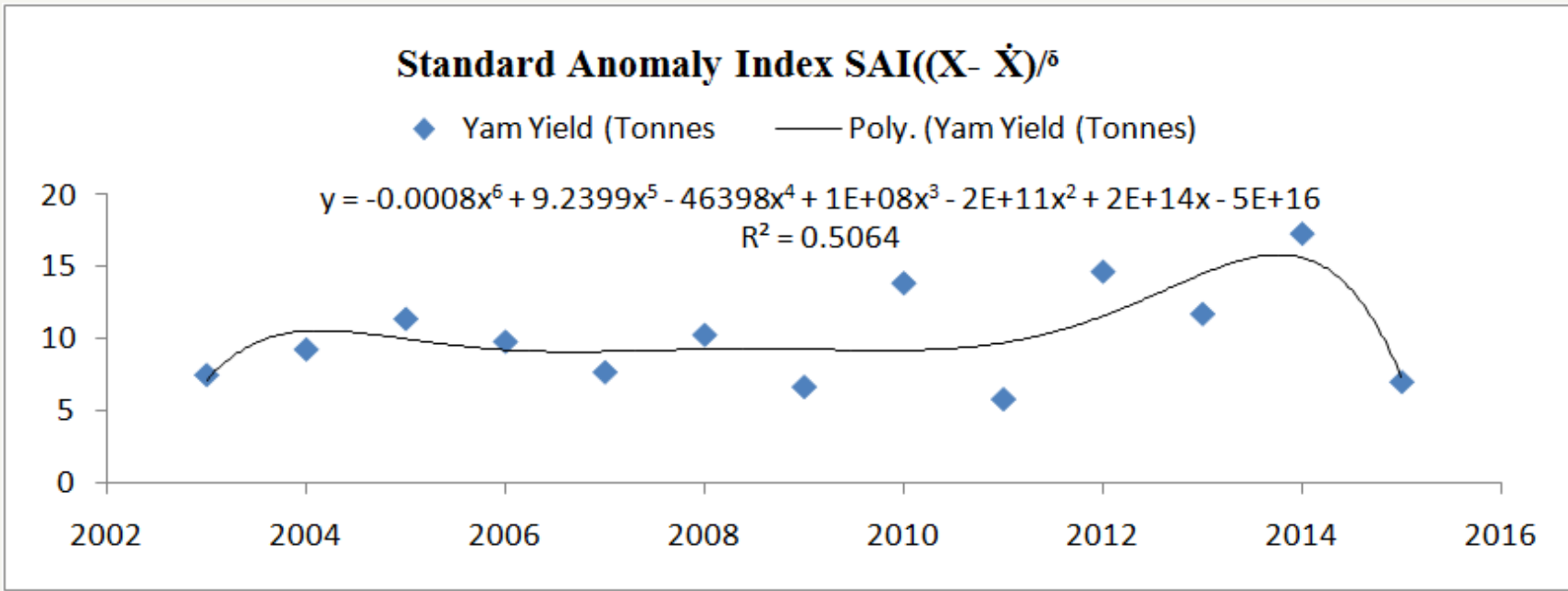

Figure 7: Trend in yam production.

\section{Conclusion and Recommendations}

\section{Conclusion}

From the findings of this research it could be concluded that strong relationship exist between annual rainfall and yam yield with $\mathrm{r} 2$ value of 0.881 within the year under review. The study also concludes that variation of time of rainfall (months) influence the yield of yam. Thereby necessitating the need for adjustment of planting time to avoid excessive rotting of Yam seeds as attested by the farmers. Also inspite of the fact that climate is changing; rainfall duration and rain days are still relatively favourable for agricultural activities in the study area. Dynamics of annual total rain fall as well as extreme events are common at the station.

\section{Recommendations}

In view of the fact that, the issue of weather parameters and precipitation effectiveness indices are becoming a major treat in agricultural planning and productivity, the study strongly recommends the following:

a) Government at all levels should see that meteorological equipment are provided to all Local development authorities, research and training institutions, departments of Geography and Agricultural Sciences and every other unit in order to facilitates and enhance the generation of climatic data nation-wide.

b) Farmers at all levels with the aid of extension agents should acquaint themselves with information from meteorological agencies in order to have an idea of the predicted rainy season so as to know the likely onset, cessation dates, rainfall, relative humidity and others as they affect the performance and yield of crops.

c) This preliminary work on rainfall-Yam relationships is not exhaustive. More could still be achieved in further studies geared towards the understanding of the interplay of weather parameters and Yam yield. There are about thirteen precipitation effectiveness indices; others could be research on such as Hydrological ratio, Seasonality index, dry spell etc.

\section{References}

1. Adeniyi EO (1980) Niger State: a survey of resources for development. Nigerian institute of social and economic research, Ibadan, Nigeria.

2. (2007) National Food Reserve Agency (NFRA) statistics on agricultural production. National food reserve agency, Nigeria federal ministry of agriculture and water resource, Abuja, Nigeria.

3. Hardaker JB, Raud BMH, Jack RA (1997) Coping with risk in agriculture. In: Hardaker JB, Raud BMH, Jack RA (Eds.), Coping with risk in agriculture. AB International Oxford, New York, USA, pp. 5-7.

4. Adejuwon SA (2004) Impacts of climate variability and climate change on crop yield in Nigeria. Lead paper presented at the stakeholders workshop on the assessment of impact and adaptation to climate change, Conference center, pp. 205-219.

5. Ziervogel G, Nyong A, Osman B, Conde C, Cortes S, et al. (2006) Climate variability and change: implications for household food security. Assessments of impacts and adaptations to climate change (AIACC). Washington DC, USA, pp. 678-691.

6. Olaniran OJ, Likofu A, Adeyemi AS (2001) Wet dry seasons in Nigeria. In: Olaniran OJ, Likofu A, Adeyemi AS (Eds.), Wet dry seasons in Nigeria, Weather (in press). 
7. Olaniran OJ (2000) Crop-climatic modeling for optimum crop yield. In climate change and natural disasters in Nigeria.

8. John BA, Paul M (2007) Implication of rainfall shocks for household income and consumption in Uganda. African Economic Research Consortium, Nairobi. AERC Research, p. 168.

9. Obioha E (2009) Climate Change, population drift and violent conflict over land resources in North Eastern Nigeria. J Hum Ecol 23(4): 311324.

10. Odjugo PAO (2010) Adaptation to climate change in the agricultural sector in the semi-arid region of Nigeria. Paper presented at the $2^{\text {nd }}$ International conference: climate, sustainability and development in semi-arid regions, Fortaleza-Ceará, Brazil.
11.Zoellick S, Robert BA (2009) Climate smart future. In: Zoellick S, Robert BA (Eds.), Climate smart future. The Nation newspapers. Vintage Press Limited, Lagos, Nigeria, p. 18.

12. Shiwachi H, Kikuno H, Fashola R, Asiedu R (2008) Enhancing offseason yam production in Nigeria. African Journal of Agricultural Research 3(6): 407-411.

13. Orkwor GC (1998) Yam production in Nigeria. In: Berthaud J, Bricas $\mathrm{N}$, mardand J (Eds.), Yam, old plant and crop for the future. Actes du Seminaire Inter. cirad intra-orstom-coraf. Montpellier, France, pp. 81-85.

14. Shiwachi H, Toyohara $\mathrm{H}$ (2005) Current status and future of yam production. Japanese Journal of Tropical Agriculture 49(5): 323-328.

\section{Your subsequent submission with Crimson Publishers will attain the below benefits}

- High-level peer review and editorial services

- Freely accessible online immediately upon publication

- Authors retain the copyright to their work

- Licensing it under a Creative Commons license

- Visibility through different online platforms

- Global attainment for your research

- Article availability in different formats (Pdf, E-pub, Full Text)

- Endless customer service

- Reasonable Membership services

- Reprints availability upon request

- One step article tracking system 